\title{
Integrated Clinical Pathway Regarding Care of Children with Typhoid Fever
}

\author{
Khadiga M.Said ${ }^{1}$, Basma R. Abd El-sadik ${ }^{2}$, and Faten S. Mahmoud ${ }^{3}$ \\ Lecturer of Pediatric Nursing ${ }^{I}$, Assistant Professor of Pediatric Nursing ${ }^{2 \& 3}$, Faculty of Nursing, Benha \\ University
}

\begin{abstract}
Typhoid fever remains a global health problem for Salmonella typhoid in pediatric population. The aim of this study was to assess the effect of integrated clinical pathway regarding care of children with typhoid fever through, assessing nurses' knowledge regarding integrated clinical pathway, designing and implementing integrated clinical pathway regarding care of children with typhoid fever and evaluating the effect of integrated clinical pathway on nurses' regarding care of children with typhoid fever. Research design: A quasiexperimental design was used. Settings: This study was carried out at Benha Fever Hospital and Toukh fever Hospital affiliated to ministry of health and population. The sample: All available nurses (62) who are working in the previously mentioned study setting and all available children (130) diagnosed with typhoid fever. Tools of data collection: Four tools were used; Tool I. Consists of six parts: Part 1: personal data of the studied nurses Part 2: Nurses' knowledge regarding integrated clinical pathway. Part 3: Nurses' knowledge regarding typhoid fever. Part 4: Nurses' knowledge regarding care of children with typhoid fever. Part 5: Nurses' knowledge regarding role of multidisciplinary health team management and Part 6: Nurses' knowledge regarding activities of integrated clinical pathway care map. Tool II. Child Medical Assessment Sheet: it include medical data regarding children with typhoid fever such as; characteristics of children. Tool III. Observation check list: it include; admission care, hand hygiene, sampling collection, dietary management, medication administration Tool IV. The integrated Clinical pathway Care Map. Results of this study revealed that, the total scores of nurses' knowledge were unsatisfactory before intervention. Whereas, their knowledge were satisfactory post intervention. Also, there were highly statistical significance differences before and after intervention and there are correlation between studied nurses' knowledge regarding integrated pathway and implementation of integrated pathway regarding care of children with typhoid fever pre and post intervention, it was revealed that there were a highly statistical significance correlation between them pre and post intervention. This study concluded that: applying of the nursing clinical pathway on children with typhoid fever will enhancing nurses' knowledge, and practice. The study recommended that: The approach of care of integrated clinical pathway can be utilized by all health team members in the different health agencies as a routine care.
\end{abstract}

Keywords: Typhoid fever, Integrated clinical pathway and Nursing Management

\section{Introduction}

Typhoid fever is a bacterial disease caused by Salmonella typhoid. It is transmitted through the ingestion contaminated of food or drink. It is thus considered one of the most serious infectious disease threats to public health spatiality in pediatric population, with particular concern over the rapid and widespread emergence of resistance to multiple antibiotics (1)

Typhoid fever was estimated 21.7 million illness and 217,000 deaths in 2000.It occurs most often in children and young adults between 5 to 9 years old. In 2013 it resulted in about 161,000 deaths down from 181,000. Infant, children, and adolescent in South-central and Southeast Asia experience the greatest burden of illness (4)

Symptoms usually develop 1-3 weeks after exposure, and may be mild or severe. They include high fever, malaise, headache, constipation or diarrhea, rose-colure spots on the chest, and enlarged spleen and liver. Healthy carrier state may follow acute illness. (2). Many factors influence the severity and overall clinical outcome of the infection. They include the duration of illness before the initiation of appropriate therapy, the choice of antimicrobial treatment, age, the previous exposure or vaccination history (3) (14)

A diagnosis of typhoid fever can usually be confirmed by analyzing samples of blood, stools or urine. These will be examined under a microscope for the Salmonella typhoid bacteria that cause the condition. The bacteria aren't always detected the first time, so you may need to have a series of tests. Testing a sample of bone marrow is a more accurate way of diagnosing typhoid fever. (5)

Complications of typhoid fever include; a bleeding or perforated intestine. This perforation in the intestine allow the contents to contaminate the child's abdominal cavity, which leads to nausea, vomiting and abdominal pain. It can also lead to septicemia. Other complications are polyarthritis, carditis, pneumonia, pancreatitis, and infections of the kidney or bladder (6) 
Supportive measures are important in the management of typhoid fever, such as oral or intravenous hydration, the use of antipyretics, and appropriate nutrition and blood transfusions if indicated. More than $90 \%$ of children can be managed at home with oral antibiotics, reliable care and close medical follow-up for complications or failure to respond to therapy. However, children with persistent vomiting, severe diarrhea and abdominal distension may require hospitalization and parenteral antibiotic therapy (7)

Care pathways are a way of setting out a process of best practice to be followed in the treatment of a patient or client with a particular condition or with particular needs. They are a distillation of the best available expert opinion on the care process and should be evidence based. Care pathways, which map out the care journey an individual can expect, should be multi-professional, crossing organizational boundaries; and can act as a prompt for care. They can also create a consistent standard of documentation which will provide the basis for ongoing audit (8) Nursing management, teach, guide and supervise members of the family on nursing techniques which will contribute to the child's recovery, interpret to family nature of disease and need for practicing preventive and control measures, demonstrate to family how to give bedside care such as tepid sponge, feeding changing of bed linen, use of bedpan and mouth care, any bleeding from the rectum, blood in stools sudden acute abdominal pain restlessness, hypothermia should be reported at once to the physician or the patient should be brought at once to the hospital and take vital signs and teach child family member how to take and record same. (9)

\title{
Significant of the study
}

Typhoid fever is a global health problem for Salmonella typhoid in pediatric population. Its real impact is difficult to estimate because the clinical picture is confused with those of many other febrile infections. Additionally, the disease is underestimated because there are no bacteriology laboratories in most areas of developing countries. These factors are believed to result in many cases going undiagnosed. So, children with typhoid fever require special care from nurses to ensure maximum nursing performance. Therefore, this study will be conducted to assess the effect of clinical pathway regarding care of children with typhoid fever.

\begin{abstract}
Aim:
The aim of this study is to assess the effect of integrated clinical pathway regarding care of children with typhoid fever through:

- $\quad$ Assessing nurses' knowledge regarding integrated clinical pathway.

- Designing and implementing integrated clinical pathway regarding care of children with typhoid fever

- Evaluating the effect of integrated clinical pathway on nurses' regarding care of children with typhoid fever
\end{abstract}

\section{Research hypothesis:}

1-There will be significant difference between pre-intervention and post-intervention knowledge score of nurses regarding management of children with typhoid fever after applying the clinical pathway intervention.

2- There will be significant difference between pre-intervention and post-intervention practice score of nurses regarding management of children with typhoid fever after applying the clinical pathway intervention.

3-There will be significant correlation between knowledge and practice scores after applying the clinical pathway intervention.

4-There will be significant relation between nurses' knowledge, and practice scores and their personal characteristics after applying the clinical pathway intervention.

\section{I- Technical Design:}

\section{Subjects and Method}

\section{Research design:}

A quasi experimental research design was utilized to achieve the aim of this study.

\section{Research Settings:}

The study was conducted in Benha Fever Hospital and Toukh fever hospital affiliated to ministry of health and population.

\section{Sampling:}

- The study sample included all available nurses (62) who are working in the previously mentioned study settings regardless of their age, educational level, years of experience, place of work, and attainment of previous courses regarding integrated clinical pathway.

- All available children (130) diagnosed with typhoid fever who are hospitalized undergoing for treatment regardless of their age, gender, birth order and length of hospital stay. 


\section{Tools of Data Collection}

\section{Tool I:}

A structured interviewing questionnaire sheet: this tool designed by the researchers based on the scientific literature to assess nurse's knowledge regarding management of children with typhoid fever. It was prepared on simple Arabic language and comprised the following parts which are:

Part 1: Personal of characteristics of studied nurses as; age, educational level, years of experience, place of work and attainment of previous courses regarding integrated clinical pathway.

Part 2: Nurses' knowledge regarding integrated clinical pathway as; definition, elements, steps, benefits, barriers, variance, causes of failure of implementing integrated clinical pathway and nursing role in clinical pathway.

Part 3: Nurses' knowledge regarding typhoid fever as; definition, leading causes, predisposing factors, manifestation, diagnosis, treatment, complications, prevention, prognosis, dietary management, hygienic measures, dangerous signs, follow-up care, parents teaching and psychological support.

Part 4: Nurses' knowledge regarding care of children with typhoid fever as; admission care, hand hygiene, sampling collection, dietary management, medication administration, maintenance of body temperature, discharge and follow-up care and parents and family education.

Part 5: Nurses' knowledge regarding role of multidisciplinary health team management during implementation of integrated clinical pathway care map in management of children with typhoid fever.

Part 6: Nurses' knowledge regarding activities of integrated clinical pathway care map which covering the phases of care of children with typhoid fever, (preparatory, curative, recovery, and discharge phase) and it include; assessment, diagnostic tests, nutrition, activity, skin care, medication. Consultation, nursing documentation and follow up.

\section{Scoring system:}

Knowledge obtained from the studied nurses was scored and calculated according to their answers. Each question had a score ranged from 0-2 grades, whereas, complete and correct answer scored 2 grades, correct but incomplete answer scored 1 grade and zero for incorrect or unknown answer. The total score level for the questionnaire was 130 grades (equal 100\%). Answers of studied nurses categorized as follow:

- $\quad$ Satisfactory knowledge (more than or equal 75\%).

- Unsatisfactory knowledge (less than 75\%).

\section{Tool II:}

Child Medical Assessment Sheet: it include medical data regarding children with typhoid fever such as; characteristics of children (age, gender, birth order, weight, main complain, prescribed diet, prescribed medication, activity allowed, past medical history length of hospital stay, diagnostic tests, and date admission and date discharge.

\section{Tool III:}

Observational check list: It was adopted from (10) and modified by the researchers to suit the Egyptian culture. It was used to assess actual nurses' practices regarding care of children with typhoid fever, it include; admission care, hand hygiene, sampling collection, dietary management, medication administration, maintenance of body temperature, discharge and follow-up care. Each nurse was observed during each procedure using nurses' observational check lists. Each step for any procedure had a score ranged from 0-2 grades, whereas, complete and correct done scored 2 grades, correct but incompletely done scored 1 grade and zero for incorrect practice. The total score level for the all procedures were 198 grades (equal 100\%). practices of studied nurses categorized as follow:

- $\quad$ Competent practice level: Equal to or more than $80 \%$.

- Incompetent practice level: Less than $80 \%$

Tool IV:

The integrated Clinical pathway Care Map: It was adopted from (11\&12) and the contents and formats were modified by the researchers to suit the Egyptian culture and the nature of the study. This model is put in a map for managing children with typhoid fever. The activities of integrated clinical pathway care map covering the phases of care from admission until discharge. The integrated clinical pathway care map using the time as follow:

\begin{tabular}{|ll|ll|}
\hline Time & & Phase & \\
\hline- & 0-2 hours & - & Initial management phase \\
\hline- & 1 to 7 days & - & Curative phase \\
\hline- & 7 to 15 days & - & Recovery phase \\
\hline- & After 15 days & - & Discharge phase \\
\hline
\end{tabular}




\section{Validity and reliability:}

Data collection tools were submitted to five experts of pediatric nursing field from the Faculty of Nursing Ain Shams, Tanta and Benha Universities, to test the content validity. Modifications of the tools were done according to the expert's judgment on clarity of sentences, appropriateness of content and sequence of items. The experts' agreed on the content, but recommended minor language changes that would make the information clearer and more precise. The suggested changes were made. Internal consistency reliability of all items of the tools was done to determine the extent to which items of the questionnaire are related to each other by cronbach's co- efficiency alpha $(\mathrm{a}=0.97)$ and was 0.83 for nurses' practices observation checklist..

\section{II- Operational Design: \\ Preparatory phase:}

The researcher did a review of the current and past local and international related literature to get acquainted with the nature of the study and to cover various aspects related to management for children with typhoid fever. This helped the researchers to develop the data collection tools.

\section{Pilot study:}

A pilot study was carried out on $10 \%$ of the total sample about (13 hospitalized child with typhoid fever and 6 nurses working at the previously mentioned study settings) from beginning of August to the end of September 2015. It was done for evaluating the applicability and clarity of the study tools, estimate time consumed for each tool for data collection, assessment of feasibility of fieldwork and detecting any obstacles that might face the researchers or interfere with data collection. The sample of studied children and nurses participated in pilot study were excluded in the main study sample.

\section{Ethical considerations:}

A permission to carry out the study obtained from the hospital manager in Benha and Toukh fever hospitals and head of departments in the previously mentioned study settings through submission of official letters issued from the dean of Benha faculty of nursing. Oral consent from nurses and each child's mother/ father were obtained after explanation of the aim of the study to them. Nurses and each child's mother $\backslash$ father were informed that participation in the study was voluntary. Each one had the right to withdraw from the study at any time without giving any reason. Confidentiality of participants' information was assured and the data were accessed only by the researchers involved in the study.

\section{Field work:}

The actual field work was carried out from the beginning of November 2015 to the end of April, 2016. A permission to conduct the study was obtained from the managers of the previously mentioned study settings. In the beginning, the researchers interviewed the nurses in the study settings at different working shifts (morning and afternoon) by rotation 3 days weekly; to give them a brief idea about the study and its purposes and an oral/ written consent was obtained. Then, the first pre-intervention structured questionnaire sheet was distributed to collect nurses' personal characteristics and to assess their knowledge regarding management of children with typhoid fever (Tool I). At the same time, the researchers were monitoring the nurses during their work to fill out the observational checklist (Tool II). The time required for complete the study tools ranged between 45- 60 minutes.

At the beginning of the first session the researchers introduce themselves to the studied nurses, a brief idea about the study and its purposes and expected outcomes were offered Simple words and Arabic language were used to suit the nurses' level of understanding.. Each nurse was interviewed individually for their knowledge assessment regarding integrated clinical pathway, and typhoid fever for $\mathbf{2 5}-\mathbf{4 0}$ minutes to fill out the structured interviewing questionnaire sheet (Tool 1). The researchers clarified and answered any related questions to correct any misunderstanding. The activities of clinical pathway care map were used to assess the nurses' knowledge regarding care of children with typhoid fever.

The integrated clinical pathway care map was filled by the studied nurses before implementing of integrated clinical pathway (pre intervention). Implementation of integrated clinical pathway care map was carried out in 12 sessions, (4sessions for theory and 8 sessions for practice) for $\mathbf{3}$ days weekly, time for each session ranged between 60- 90 minutes. Nurses were divided into 12 groups, from 5 to 6 nurses in each group. These sessions have lasted for $\mathbf{2 0}$ hours (4 hours for theory \& $\mathbf{1 6}$ hours for practice), started from $\mathbf{1 1}$ Am which was a suitable time for nurses because the time from 8 to $11 \mathrm{Am}$, they were so busy with providing nursing care for children.

The theoretical part focused on knowledge regarding integrated clinical pathway as; definition, elements, steps, benefits, barriers, variance, causes of failure of implementing integrated clinical pathway and nursing role in clinical pathway. In addition, Nurses' knowledge regarding activities of integrated clinical 
pathway care map which covering the phases of care of children with typhoid fever, (preparatory, curative, recovery, and discharge phase) and it include; assessment, diagnostic tests, nutrition, activity, skin care, medication. Consultation, nursing documentation and follow up. Also, theoretical part focus on nurses' knowledge regarding role of multidisciplinary health team management during implementation of integrated clinical pathway care map in management of children with typhoid fever. As well as knowledge about typhoid fever which include: definition, leading causes, predisposing factors, manifestation, diagnosis, treatment, complications, prevention, prognosis, dietary management, hygienic measures, dangerous signs, follow-up care, parents teaching and psychological support. Meanwhile, the practical parts cover the procedures of care of children with typhoid fever, which include: admission care, hand hygiene, sampling collection, dietary management, medication administration, maintenance of body temperature, discharge and follow-up care. The researchers started each session with a summary for the previous one.

The researchers provide effective program for studied nurses regarding application of integrated clinical pathway care map regarding care of children with typhoid fever through using different teaching strategies such as lectures, small group discussion, brain storming, role play, demonstration and redemonstration using real objects. Suitable teaching aids as booklet, colored posters, doll and real objects were prepared especially for implementation of the intervention. Proper audio-visual materials such as data show were used in order to help proper understanding of contents by nurses. They were motivated to cooperate and participate actively in different stages of the study. After application of the integrated clinical pathway care map, the post intervention was applied to evaluate the nurses' knowledge regarding the effect of integrated clinical pathway care map in care of children with typhoid fever using the same pre intervention tools.

\section{Statistical analysis}

All data were collected, coded, tabulated and analyzed by using SPSS (Statistical Package for the social Science Software) statistical package version 20 on IBM compatible computer. Quantitative variables were described by the Mean, Standard deviation $(X \pm S D)$, while qualitative variables were expressed as frequency and percentage and chi-square $\left(\mathrm{X}^{2}\right)$ was used. Pearson correlation $(\mathrm{r})$ was used to measure the correlation between quantitative variables, while student t-test was used for comparing the means of two groups. One way ANOVA F-test was used for comparing the means of more than two groups of quantitative variables. A significant level value was considered when $p$-value $\leq 0.05$ and a highly significant level value was considered when $\mathrm{p}$-value $\leq 0.001$, while $\mathrm{p}$-value $>0.05$ indicates non-significant results.

\section{Results}

Table (1) shows the nurses' personal characteristics; it was observed that, the mean age of them were $32 \pm 2.7$ years. Majority of nurses were females and about half of them $(51.6 \%)$ had years of experiences ranged from 1 to less than 10 years. In relation to nurses' education, more than three quarters of them (79.0\%) of them had diploma in nursing, while $11.3 \%$ of them had Bachelor degree in nursing. Also, it was noticed that $90.3 \%$ of them not attended any previous training courses regarding nursing management of typhoid fever.

Table (2) reveals that, the personal characteristics of the studied children; it was observed that, the mean age of them were $12.2 \pm 2.6$ years. More than half of them (58.5) were females and $30.0 \%$ of them were the first in order. In relation to their complains from typhoid fever, the majority of them (85.4\%) of them had fever, vomiting, headache and abdominal pain, while $3.1 \%$ of them had vomiting or abdominal pain only. Also, it was noticed that, more than three quarters of them (75.4\%), their symptoms started more than one week ago.

Table (3) and figure (3): This figure show that all studied nurses have unsatisfactory knowledge regarding integrated clinical pathway pre intervention compared to $4.8 \%$ of them post intervention.

Table (4) shows nurses' knowledge regarding typhoid fever pre and post intervention. It was found that, there was a highly statistically significant difference $(\mathrm{p}<0.001)$ before and after the intervention where majority of nurses had satisfactory knowledge after the intervention regarding definition, leading causes, predisposing factors, signs and symptoms, diagnosis, treatment, complications, prevention, prognosis, dietary management, hygienic measures, prognosis and dangerous signs, follow-up care, parents teaching and psychological support.

Table (5) shows nurses' knowledge regarding care of children with typhoid fever pre and post intervention. It was found that, there was a highly statistically significant difference $(p=<0.00)$ before and after the intervention where, the majority of nurses had satisfactory practical knowledge post intervention related to all items of care provided for these children.

Table( 6) shows the total scores of knowledge of the studied nurses regarding integrated clinical pathway, typhoid fever, care of children with typhoid fever, Role of multidisciplinary health team in implementing clinical pathway and Activities of integrated clinical pathway pre and post intervention; the total scores of nurses' knowledge were unsatisfactory before intervention. Whereas, their knowledge were 
satisfactory post intervention. Also, there were highly statistical significance differences before and after intervention (P value 0.000).

Table (7) shows highly statistical significance relations between studied nurses' knowledge regarding integrated pathway and implementation of integrated pathway and their ages, educational level and years of experiences, on the other hand, there was no statistical significance between gender and their knowledge

Table (8) shows correlation between studied nurses' knowledge regarding integrated pathway and implementation of integrated pathway regarding care of children with typhoid fever pre and post intervention, it was revealed that there were a highly statistical significance correlation between them pre and post intervention

Table (1): Number and percentage distribution regarding personal characteristics of studied nurses $(n=62)$.

\begin{tabular}{|c|c|c|}
\hline \multirow{2}{*}{ Characteristics } & \multicolumn{2}{|c|}{$\begin{array}{c}\text { Study group } \\
\mathrm{N}=62\end{array}$} \\
\hline & No & $\%$ \\
\hline \multicolumn{3}{|l|}{ Age in years } \\
\hline$<20$ Years & 0 & 0.0 \\
\hline $20-<25$ Years & 21 & 33.9 \\
\hline $25-<30$ Years & 37 & 59.7 \\
\hline$\geq 30$ Years & 4 & 6.4 \\
\hline \multicolumn{3}{|c|}{ Mean \pm SD: $32 \pm 2.7$} \\
\hline \multicolumn{3}{|l|}{ Gender } \\
\hline Male & 3 & 4.8 \\
\hline Female & 59 & 95.2 \\
\hline \multicolumn{3}{|l|}{ Experience (years): } \\
\hline$<$ lyear & 9 & 14.5 \\
\hline $1-<10$ years & 32 & 51.6 \\
\hline$\geq 10$ years & 21 & 33.9 \\
\hline \multicolumn{3}{|l|}{ Academic Qualification } \\
\hline Diploma (Secondary School) & 49 & 79.0 \\
\hline Technical Institute of Nursing & 6 & 9.7 \\
\hline Bachelor of Nursing & 7 & 11.3 \\
\hline \multicolumn{3}{|l|}{ Job description } \\
\hline - $\quad$ Nurses & 55 & 88.7 \\
\hline - $\quad$ Supervisors & 7 & 11.3 \\
\hline \multicolumn{3}{|l|}{ Attendance of previous training courses } \\
\hline yes & 6 & 9.7 \\
\hline No & 56 & 90.3 \\
\hline
\end{tabular}

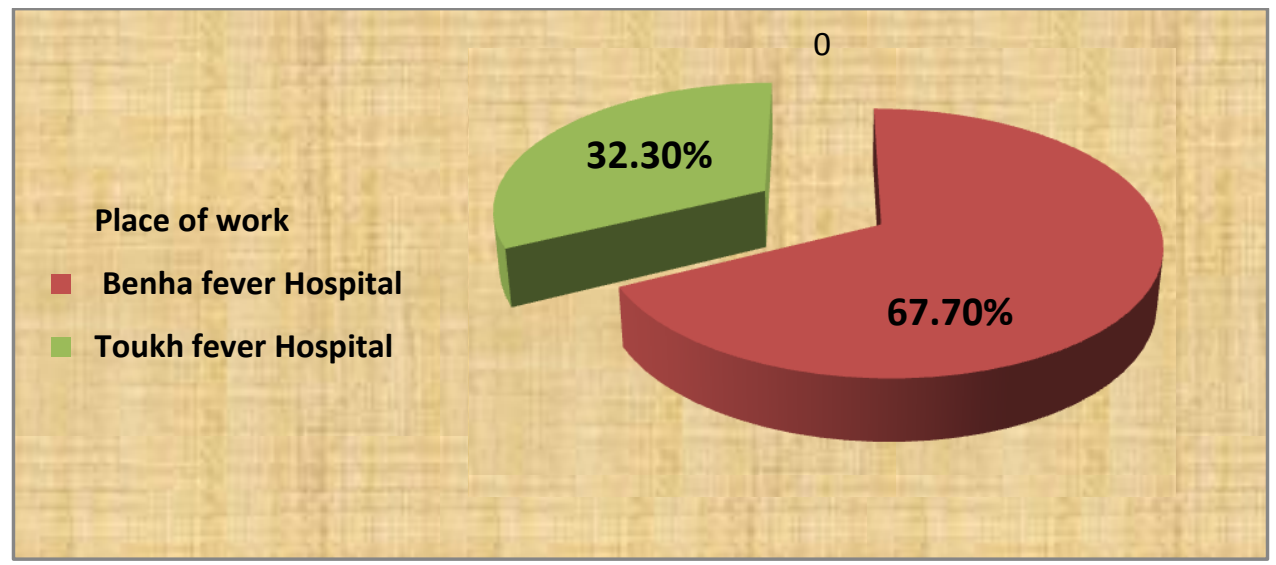

Figure (1): Distribution of the studied nurses regarding their place of work N: (62).

This figure shows that more than two third of studied nurses working at benha fever hospital affliated to ministry of health and population. 
Table (2): Number and percentage distribution regarding personal characteristics of studied children $(\mathrm{n}=130)$.

\begin{tabular}{|c|c|c|}
\hline \multirow{2}{*}{ Characteristics } & \multicolumn{2}{|c|}{$\begin{array}{c}\text { Study group } \\
\mathrm{N}=130\end{array}$} \\
\hline & No & $\%$ \\
\hline \multicolumn{3}{|l|}{ Age in years } \\
\hline$<5$ & 28 & 21.5 \\
\hline $5-<10$ & 39 & 30.0 \\
\hline $10-<15$ & 34 & 26.2 \\
\hline 15 and more & 29 & 22.3 \\
\hline \multicolumn{3}{|l|}{ Mean \pm SD: $12.2 \pm 2.6$} \\
\hline \multicolumn{3}{|l|}{ Gender } \\
\hline Male & 54 & 41.5 \\
\hline Female & 76 & 58.5 \\
\hline \multicolumn{3}{|l|}{ Child rank } \\
\hline First & 39 & 30.0 \\
\hline second & 29 & 22.3 \\
\hline third & 28 & 21.5 \\
\hline fourth and more & 34 & 26.2 \\
\hline \multicolumn{3}{|l|}{ Main complains: } \\
\hline Fever & 5 & 3.8 \\
\hline Vomiting & 4 & 3.1 \\
\hline Headache & 6 & 4.6 \\
\hline Abdominal pain & 4 & 3.1 \\
\hline All of the above & 111 & 85.4 \\
\hline \multicolumn{3}{|l|}{ Date symptoms started } \\
\hline Less than three days ago & 9 & 6.9 \\
\hline From three to seven days ago & 23 & 17.7 \\
\hline More than one week ago & 98 & 75.4 \\
\hline
\end{tabular}

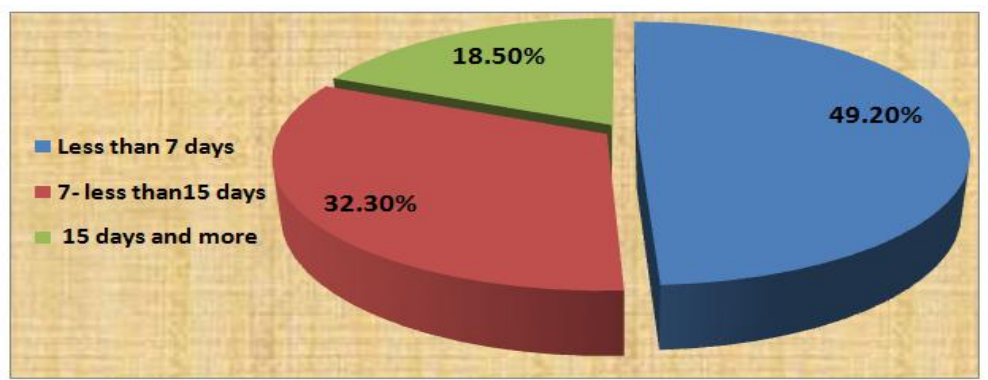

Figure (2): Distribution of the studied children regarding their length of hospital stay N: (130).

Regarding the length of hospital stay for studied children, it was found that, $49.2 \%$ of them their hospital stay less than 7 days, while, $18.5 \%$ of them stay more than 15 days in the hospital.

Table (3): Percentage Distribution of the studied nurses according to their Knowledge about integrated clinical pathway pre and post intervention (n: 62)

\begin{tabular}{|c|c|c|c|c|c|c|c|c|c|c|}
\hline \multirow{3}{*}{ Items of Knowledge } & \multicolumn{4}{|c|}{ Pre intervention (62) } & \multicolumn{4}{|c|}{ Post intervention (62) } & \multirow{3}{*}{$x^{2}$} & \multirow[t]{3}{*}{ P value } \\
\hline & \multicolumn{2}{|c|}{ Satisfactory } & \multicolumn{2}{|c|}{ Unsatisfactory } & \multicolumn{2}{|c|}{ Satisfactory } & \multicolumn{2}{|c|}{ Unsatisfactory } & & \\
\hline & No & $\%$ & No & $\%$ & No & $\%$ & No & $\%$ & & \\
\hline $\begin{array}{lccc}\begin{array}{l}\text { Definition } \\
\text { pathway }\end{array} & \text { of integrated } & \text { clinical } \\
\end{array}$ & 5 & 8.0 & 57 & 92.0 & 60 & 96.8 & 2 & 3.2 & 33.41 & $0.001 * *$ \\
\hline Elements of integrated clinical pathway & 3 & 4.8 & 59 & 95.2 & 58 & 93.6 & 4 & 6.4 & 40.11 & $0.001 * *$ \\
\hline Steps of integrated clinical pathway & 5 & 8.0 & 57 & 92.0 & 58 & 93.6 & 4 & 6.4 & 38.04 & $0.001 * *$ \\
\hline $\begin{array}{l}\text { Benefits of integrated clinical pathway } \\
\text { For nurses }\end{array}$ & 1 & 1.6 & 61 & 98.4 & 62 & 100.0 & 0 & 0.0 & 38.19 & $0.000 * *$ \\
\hline For children & 0 & 0.0 & 62 & 100.0 & 59 & 95.2 & 3 & 4.8 & 36.08 & $0.001 * *$ \\
\hline Variance types & 0 & 0.0 & 62 & 100.0 & 58 & 93.6 & 4 & 6.4 & 32.74 & $0.001^{* *}$ \\
\hline Reasons of variance & 0 & 0.0 & 62 & 100.0 & 62 & 100.0 & 0 & 0.0 & 42.16 & $0.00 * *$ \\
\hline $\begin{array}{l}\text { Causes of failure of implementing } \\
\text { integrated clinical pathway }\end{array}$ & 7 & 11.3 & 55 & 88.7 & 60 & 96.8 & 2 & 3.2 & 31.55 & $0.001^{* *}$ \\
\hline Nursing role in clinical pathway & 1 & 1.6 & 61 & 98.4 & 60 & 96.8 & 2 & 3.2 & 38.19 & $0.000^{* * *}$ \\
\hline Total & $\mathbf{0}$ & 0.0 & 62 & 100.0 & 59 & 95.2 & 3 & 4.8 & 21.47 & 0.001 ** \\
\hline
\end{tabular}




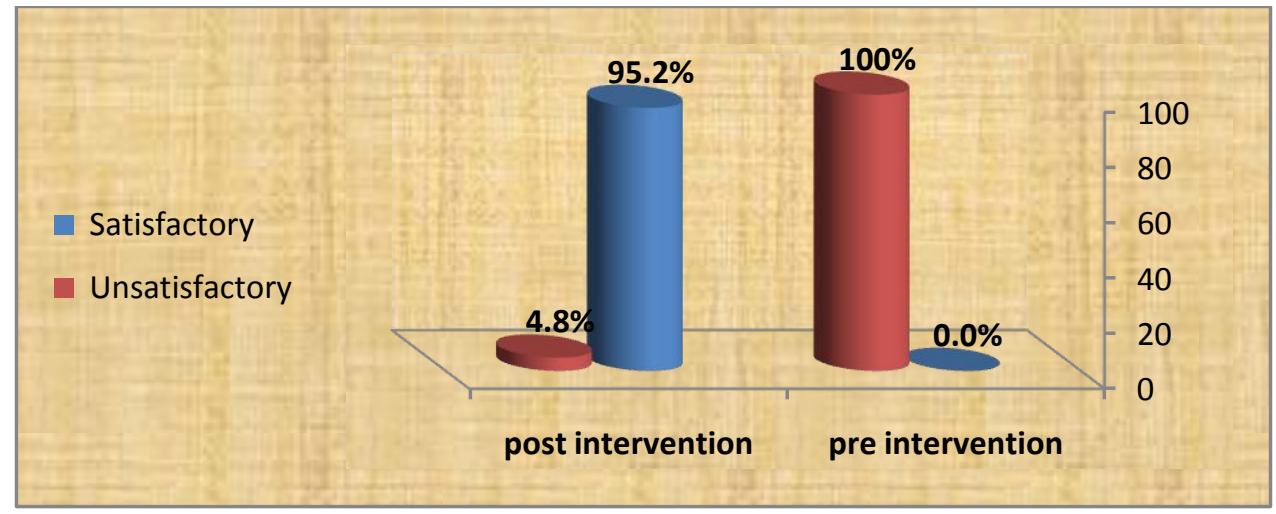

Fig. (3): Percentage Distribution of the Studied nurses according to their Total Knowledge about integrated clinical pathway pre and post intervention (n: 62)

This figure show that all studied nurses have unsatisfactory knowledge regarding integrated clinical pathway pre intervention compared to $4.8 \%$ of them post intervention.

Table (4): Percentage Distribution of the studied nurses according to their Knowledge about Typhoid fever pre and post intervention (n: 62)

\begin{tabular}{|c|c|c|c|c|c|c|c|c|c|c|}
\hline \multirow{3}{*}{ Items of Knowledge } & \multicolumn{4}{|c|}{ Pre intervention (62) } & \multicolumn{4}{|c|}{ Post intervention (62) } & & \multirow[t]{3}{*}{ P value } \\
\hline & \multicolumn{2}{|c|}{ Satisfactory } & \multicolumn{2}{|c|}{ Unsatisfactory } & \multicolumn{2}{|c|}{ Satisfactory } & \multicolumn{2}{|c|}{ Unsatisfactory } & & \\
\hline & No & $\%$ & No & $\%$ & No & $\%$ & No & $\%$ & & \\
\hline 1. Definition of typhoid fever & 7 & 11.3 & 55 & 88.7 & 60 & 96.8 & 2 & 3.2 & 33.41 & $0.001^{* * *}$ \\
\hline 2. Leading causes & 3 & 4.8 & 59 & 95.2 & 58 & 93.6 & 4 & 6.4 & 40.11 & $0.001^{* *}$ \\
\hline 3. $\quad$ Predisposing factors & 5 & 8.0 & 57 & 92.0 & 55 & 88.7 & 7 & 11.3 & 38.04 & $0.001^{* * *}$ \\
\hline 4. Signs and symptoms & 1 & 1.6 & 61 & 98.4 & 62 & 100.0 & 0 & 0.0 & 38.19 & $0.000^{* *}$ \\
\hline 5. Diagnosis & 0 & 0.0 & 62 & 100.0 & 59 & 95.2 & 3 & 4.8 & 36.08 & $0.001^{* * *}$ \\
\hline 6. Treatment & 0 & 0.0 & 62 & 100.0 & 58 & 93.6 & 4 & 6.4 & 32.74 & $0.001^{* *}$ \\
\hline 7. $\quad$ Complications & 0 & 0.0 & 62 & 100.0 & 62 & 100.0 & 0 & 0.0 & 42.16 & $0.00^{* * *}$ \\
\hline 8. $\quad$ Prevention & 7 & 11.3 & 55 & 88.7 & 60 & 96.8 & 2 & 3.2 & 31.55 & $0.001^{* *}$ \\
\hline 9. $\quad$ Prognosis & 1 & 1.6 & 61 & 98.4 & 62 & 100.0 & 0 & 0.0 & 38.19 & $0.000^{* * *}$ \\
\hline 10. Dietary management & 0 & 0.0 & 62 & 100.0 & 62 & 100.0 & 0 & 0.0 & 42.16 & $0.00^{* * *}$ \\
\hline 11. Hygienic measures & 7 & 11.3 & 55 & 88.7 & 60 & 96.8 & 2 & 3.2 & 31.55 & $0.001^{* *}$ \\
\hline 12. Prognosis and dangerous signs & 1 & 1.6 & 61 & 98.4 & 62 & 100.0 & 0 & 0.0 & 38.19 & $0.000^{* * *}$ \\
\hline 13. Follow-up care & 5 & 8.0 & 57 & 92.0 & 58 & 93.6 & 4 & 6.4 & 36.71 & $0.001^{* *}$ \\
\hline 14. Parents teaching & 3 & 4.8 & 59 & 95.2 & 58 & 93.6 & 4 & 6.4 & 33.92 & $0.00^{* *}$ \\
\hline 15. Psychological support & 4 & 6.4 & 58 & 93.6 & 50 & 80.6 & 12 & 19.4 & 29.18 & 0.00 \\
\hline Total & 3 & 4.8 & 59 & 95.2 & 58 & 93.6 & 4 & 6.4 & 18.64 & $0.001 * *$ \\
\hline
\end{tabular}

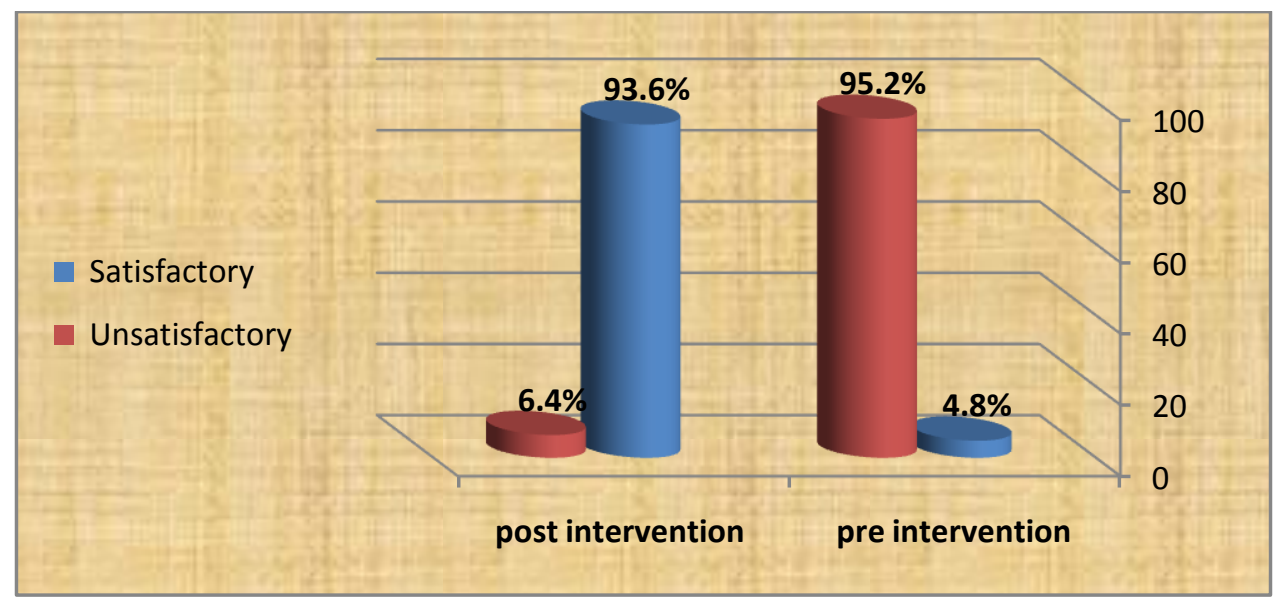

Fig. (4): Percentage Distribution of the Studied nurses according to their Total Knowledge about typhoid fever pre and post intervention (n: 62) 
Table (5): Percentage Distribution of the studied nurses according to their Knowledge about Care of children with Typhoid fever pre and post intervention implementation (n: 62)

\begin{tabular}{|c|c|c|c|c|c|c|c|c|c|c|}
\hline \multirow{3}{*}{ Items } & \multicolumn{4}{|c|}{ Pre intervention (62) } & \multicolumn{4}{|c|}{ Post intervention (62) } & \multirow{3}{*}{$x^{2}$} & \multirow{3}{*}{$P$ value } \\
\hline & \multicolumn{2}{|c|}{ Satisfactory } & \multicolumn{2}{|c|}{ Unsatisfactory } & \multicolumn{2}{|c|}{ Satisfactory } & \multicolumn{2}{|c|}{ Unsatisfactory } & & \\
\hline & No & $\%$ & No & $\%$ & No & $\%$ & No & $\%$ & & \\
\hline 1- $\quad$ Admission care & 3 & 4.8 & 59 & 95.2 & 60 & 96.8 & 2 & 3.2 & \multirow{15}{*}{22.36} & \multirow{15}{*}{$0.000^{* *}$} \\
\hline 2- Hand hygiene & 7 & 11.3 & 55 & 88.7 & 62 & 100.0 & 0 & 0.0 & & \\
\hline $\begin{array}{ll}\text { 3- } & \text { Sampling collection } \\
\text { a- } & \text { Blood }\end{array}$ & 18 & 29.0 & 44 & 71.0 & 62 & 100.0 & 0 & 0.0 & & \\
\hline b- urine & 12 & 19.4 & 50 & 80.6 & 60 & 96.8 & 2 & 3.2 & & \\
\hline c- $\quad$ Stool & 16 & 25.8 & 46 & 74.2 & 55 & 88.7 & 7 & 11.3 & & \\
\hline $\begin{array}{ll}\text { 4- } & \text { Dietary management } \\
\text { a- } & \text { Proper food management }\end{array}$ & 1 & 1.6 & 61 & 98.4 & 59 & 95.2 & 3 & 4.8 & & \\
\hline b- Proper fluid management & 7 & 11.3 & 55 & 88.7 & 55 & 88.7 & 7 & 11.3 & & \\
\hline $\begin{array}{ll}\text { 5- } & \text { Medication administration } \\
\text { a- } & \text { Oral medication administration } \\
\end{array}$ & 3 & 4.8 & 59 & 95.2 & 58 & 93.6 & 4 & 6.4 & & \\
\hline b- I V Medication administration & 7 & 11.3 & 55 & 88.7 & 60 & 96.8 & 2 & 3.2 & & \\
\hline c- IM Medication administration & 7 & 11.3 & 55 & 88.7 & 62 & 100.0 & 0 & 0.0 & & \\
\hline $\begin{array}{l}\text { 6- Maintenance of body temperature } \\
\text { a- } \quad \text { Oral temperature }\end{array}$ & 6 & 9.7 & 56 & 90.3 & 60 & 96.8 & 2 & 3.2 & & \\
\hline b- Axillary temperature & 3 & 4.8 & 59 & 95.2 & 62 & 100.0 & 0 & 0.0 & & \\
\hline 7- Discharge and follow-up care & 6 & 9.7 & 56 & 90.3 & 57 & 91.9 & 5 & 8.1 & & \\
\hline 8- Parents and family education & 2 & 3.2 & 60 & 96.8 & 62 & 100.0 & 0 & 0.0 & & \\
\hline Total & 5 & 8.0 & 57 & 92.0 & 58 & 93.6 & 4 & 6.4 & & \\
\hline
\end{tabular}

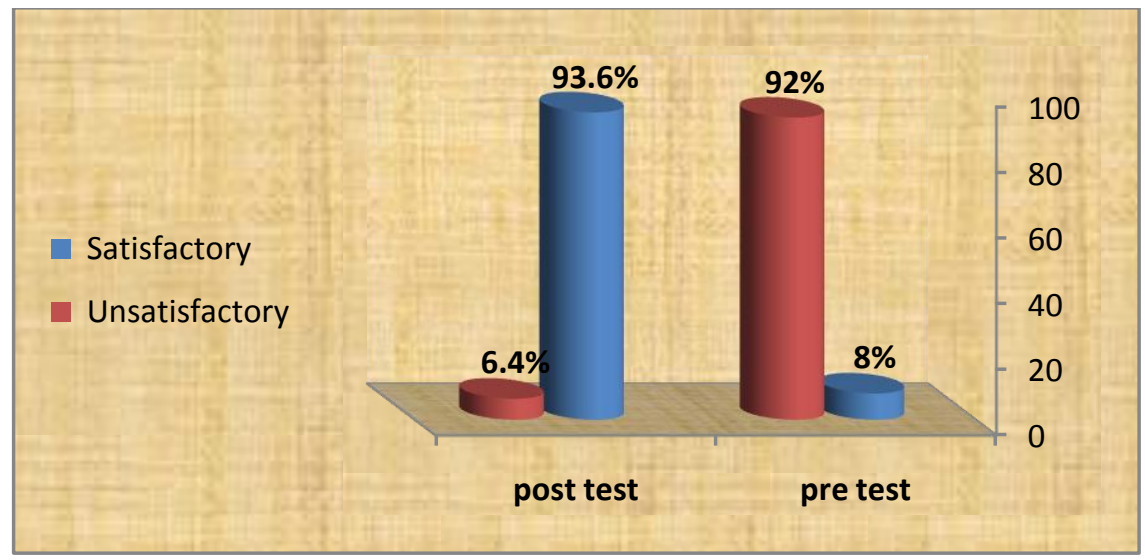

Fig. (5): Percentage Distribution of the Studied nurses according to their Total Knowledge about care of children with typhoid fever pre and post intervention (n: 62)

Table (6): Number and percentage distribution of total scores of knowledge of the studied nurses' pre and post intervention (n: 62)

\begin{tabular}{|c|c|c|c|c|c|c|c|c|}
\hline \multirow{2}{*}{\multicolumn{3}{|c|}{ Items of Knowledge regarding }} & \multicolumn{2}{|c|}{$\begin{array}{c}\text { Pre intervention } \\
(62)\end{array}$} & \multicolumn{2}{|c|}{$\begin{array}{c}\text { Post intervention } \\
(62)\end{array}$} & & \multirow[t]{2}{*}{$P$ value } \\
\hline & & & No & $\%$ & No & $\%$ & & \\
\hline \multirow{2}{*}{ Integrated clinical pathway } & - & Satisfactory & 0 & 0.0 & 59 & 95.2 & \multirow[b]{2}{*}{21.47} & \multirow{2}{*}{$0.001 * *$} \\
\hline & - & Unsatisfactory & 62 & 100.0 & 3 & 4.8 & & \\
\hline \multirow{2}{*}{ Typhoid fever } & - & Satisfactory & 3 & 4.8 & 58 & 93.6 & \multirow[t]{2}{*}{18.64} & \multirow{2}{*}{$0.001^{* *}$} \\
\hline & - & Unsatisfactory & 59 & 95.2 & 4 & 6.4 & & \\
\hline \multirow{2}{*}{ Care of children with typhoid fever } & - & Satisfactory & 5 & 8.0 & 58 & 93.6 & \multirow{2}{*}{22.36} & \multirow{2}{*}{$0.000^{* *}$} \\
\hline & 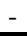 & Unsatisfactory & 57 & 92.0 & 4 & 6.4 & & \\
\hline \multirow{2}{*}{$\begin{array}{l}\text { Role of multidisciplinary health } \\
\text { team }\end{array}$} & - & Satisfactory & 3 & 4.8 & 57 & 91.9 & \multirow{2}{*}{21.12} & \multirow[t]{2}{*}{$0.000^{* * 7}$} \\
\hline & - & Unsatisfactory & 59 & 95.2 & 5 & 8.1 & & \\
\hline \multirow{2}{*}{$\begin{array}{l}\text { Activities of integrated clinical } \\
\text { pathway }\end{array}$} & - & Satisfactory & 1 & 1.6 & 55 & 88.7 & \multirow{2}{*}{19.94} & \multirow[t]{2}{*}{$0.000^{* *}$} \\
\hline & - & Unsatisfactory & 61 & 98.4 & 7 & 11.3 & & \\
\hline
\end{tabular}


Table (7): Relation between studied nurses' knowledge regarding Integrated Pathway and implementation of Integrated Pathway and their personal characteristics (n: 62)

\begin{tabular}{|c|c|c|c|c|c|c|c|}
\hline \multirow{2}{*}{$\begin{array}{c}\text { personal } \\
\text { characteristics }\end{array}$} & \multicolumn{2}{|c|}{$\begin{array}{l}\text { Nurses' Knowledge } \\
\text { Integrated Pathway }\end{array}$} & \multicolumn{2}{|c|}{ ANOVA } & \multirow{2}{*}{$\begin{array}{c}\begin{array}{c}\text { Nurses' Knowledge } \\
\text { implementation of } \\
\text { Integrated Pathway }\end{array} \\
\text { Mean+SD } \\
\end{array}$} & \multicolumn{2}{|c|}{ ANOVA } \\
\hline & $\begin{array}{c}\text { N0: } \\
62\end{array}$ & Mean+SD & $\begin{array}{l}\text { F/T } \\
\text { test }\end{array}$ & $\begin{array}{c}\mathbf{P} \\
\text { value }\end{array}$ & & $\begin{array}{l}\text { F/T } \\
\text { test }\end{array}$ & $\begin{array}{c}\mathbf{P} \\
\text { value }\end{array}$ \\
\hline \multicolumn{8}{|l|}{ Age in years } \\
\hline$<20$ & 0 & $62.61 \pm 6.35$ & \multirow{4}{*}{$\begin{array}{c}\text { F test } \\
4.82\end{array}$} & \multirow{4}{*}{0.001} & $88.74+2.34$ & \multirow{4}{*}{$\begin{array}{l}\text { F test } \\
0.852\end{array}$} & \multirow{4}{*}{0.001} \\
\hline $20-<25$ & 21 & $58.85 \pm 7.08$ & & & $90.81+3.28$ & & \\
\hline $25-<30$ & 37 & $49.09 \pm 4.66$ & & & $92.22+1.86$ & & \\
\hline$\geq 30$ & 4 & $48.03 \pm 2.23$ & & & $93.23+2.28$ & & \\
\hline \multicolumn{8}{|l|}{ Gender: } \\
\hline Male & 3 & $48.82+6.58$ & \multirow{2}{*}{$\begin{array}{l}\text { T test } \\
3.62\end{array}$} & \multirow{2}{*}{0.058} & $96.55+4.28$ & \multirow{2}{*}{$\begin{array}{l}\text { T test } \\
0.806\end{array}$} & \multirow{2}{*}{0.062} \\
\hline Female & 59 & $48.18 \pm 4.16$ & & & $95.32+3.62$ & & \\
\hline \multicolumn{8}{|l|}{ Educational level } \\
\hline Diploma & 49 & $42.31+2.38$ & \multirow{3}{*}{$\begin{array}{c}\text { F test } \\
4.02\end{array}$} & \multirow{3}{*}{0.00} & $96.14+4.32$ & \multirow{3}{*}{$\begin{array}{l}\text { F test } \\
0.738\end{array}$} & \multirow{3}{*}{$0.00^{* *}$} \\
\hline Technical & 6 & $48.45+1.98$ & & & $98.61+3.88$ & & \\
\hline Bachelor & 7 & $49.36+2.64$ & & & $93.62+2.82$ & & \\
\hline \multicolumn{8}{|l|}{ Years of experience } \\
\hline$<1$ year & 9 & $40.36+4.32$ & \multirow{3}{*}{$\begin{array}{c}\text { F test } \\
2.96\end{array}$} & \multirow{3}{*}{0.00} & $80.70+3.39$ & \multirow{3}{*}{$\begin{array}{l}\text { F test } \\
0.842\end{array}$} & \multirow{3}{*}{$0.00^{* *}$} \\
\hline $1-<10$ years & 32 & $38.44+1.48$ & & & $92.48+3.46$ & & \\
\hline$\geq 10$ years & 21 & $39.39+2.33$ & & & $93.12+2.88$ & & \\
\hline
\end{tabular}

$P$ Value $\square \mathbf{0 . 0 5}$ Statistical significant differences

$P$ value $\square \mathbf{0 . 0 1}$ high Statistical significant differences

Table (8): Correlation between studied nurses' knowledge regarding Integrated Pathway and implementation of Integrated Pathway (n: 62)

\begin{tabular}{|l|c|c|c|c||}
\hline \multicolumn{1}{|c|}{ Items } & \multicolumn{2}{|c|}{ Pre intervention (62) } & \multicolumn{2}{|c|}{ Post intervention (62) } \\
\cline { 2 - 5 } & $\mathbf{r}$ & $\mathbf{p}$ & $\mathbf{r}$ & $\mathbf{p}$ \\
\hline Nurses' Knowledge regarding Integrated Pathway & 0.864 & $0.000^{* *}$ & 0.668 & $0.000^{* * *}$ \\
\hline Nurses' Knowledge regarding implementation of Integrated Pathway & 0.960 & $0.000^{* *}$ & 0.790 & $0.000^{* *}$ \\
\hline
\end{tabular}

$P$ Value $\square \mathbf{0 . 0 5}$ Statistical significant differences (S);

$P$ value $\square \mathbf{0 . 0 1}$ high Statistical significant differences (HS).

\section{Discussion}

Integrated care pathways are one way of managing, monitoring and recording a child's care. They can also be referred to as 'clinical pathways' or 'critical pathways', 'care plans', 'care paths' and 'care maps'. In addition, an integrated care pathway must contain the following; an explicit statement of the goals and key elements of care based on evidence, best practice and patient expectations, facilitation of communication, coordination of roles and sequencing the activities of the multidisciplinary team, patients and their relatives, documentation, monitoring and evaluation of variances and outcomes, and identification of appropriate resources (13). Therefore, this study was conducted to assess nurses' knowledge regarding integrated clinical pathway, design, implement, and evaluate the effect of integrated clinical pathway on nurses' regarding care of children with typhoid fever. Typhoid fever remains a global health problem for Salmonella typhi. It is difficult to estimate the real burden of typhoid fever in the world because the clinical picture is confused with many other febrile infections, and the disease is underestimated because of the lack of laboratory resources in most areas in developing countries (9). The study involved 62 nurses working at Benha Fever Hospital. They were mostly young age, with more than half of them holding a diploma in nursing. Regarding the personal characteristics of the studied nurse, the findings of the current study revealed that, the mean age of their ages was $32 \pm 2.7$ years. These results in contrast with (14) in a study about" effect of clinical pathway regarding to care of neonates on noninvasive continuous positive airway pressure", who found that the mean age of nurses was $24.5 \pm 6.16$ years. Also, (15) in a study about "Assessment of pediatric nurses' performance regarding oxygen administration therapy", who found that, all of nurses whose age ranging from 20 to less than 25 years are the most capable group for understanding and applying what they have been taught as compared with nurses whose age from 25 to less than 30 years. As regards characteristics of the studied nurses, the current study results revealed that the highest percentage of them were female that might due to the study of nursing at Egypt was exclusive for females only till few years ago, thus the profession of nursing in Egypt was mostly feminine. Majority of them having diploma nursing degree and had years of experiences ranged from one to less than ten years. This finding was supported by (16) who assess the impact of a designed instructional program about enteral nutrition on the nurses' knowledge and practices at the critical care department and found that the highest percentage of them 
were females and having diploma in nursing. The findings of the current study revealed that, only one third of the nurses had received related training courses. This along with their young age, low experience and lower level of nursing qualification is expected to have an impact on their knowledge and practice which were revealed to be very low at the pre-intervention phase. In line with this present study finding, (14); has reported that only less than $1 \%$ of registered nurses are estimated to have any specialist typhoid training courses. Additionally, nurses not received training courses regarding integrated clinical pathway

Regarding nurses' knowledge about integrated clinical pathway pre and post intervention, the results of present study revealed that, there was a highly statistical significance differences. These results were in agreement with (17) in a study about" nursing care of children undergoing bone marrow transplantation" who found that a very high statistical significance differences was observed regarding nurses' knowledge before and after implementation of integrated clinical pathway.

On assessing the total nurses' knowledge regarding integrated clinical pathway before and after implementation, the present study clarifies that, all the studied nurses had unsatisfactory knowledge pre intervention, while the majority of them had satisfactory knowledge post intervention. These results in agreement with (17), who found that, the majority of studied nurses had poor knowledge regarding integrated clinical pathway pre intervention, while the majority of them had a good knowledge post intervention.

Regarding nurses' knowledge about Implementation of activities of integrated clinical pathway care map in care of children with typhoid fever pre and post intervention, the results of present study revealed that, there was a highly statistical significance differences. These results were in agreement with (15) in a study about" effect of clinical pathway regarding to care of neonates on noninvasive continuous positive airway pressure", who found that, clinical pathway is considered an effective nursing educational tool, it enhances the quality of care provided for patient. Also, these results agreed with (18) in a study about" Impact of a designed nursing clinical pathway on the outcomes of patients with acute heart failure at the critical care department of the El-Manial university hospital" who found that a highly statistical significance differences. Additionally, (19) in a study about "Effect of a clinical pathway on outcomes of children with hemolytic anemia" who found that a highly statistical significance differences between the study and control group regarding activities of clinical pathway. Regarding nurses' knowledge about typhoid fever, the results of present study revealed that, the majority of nurses had satisfactory knowledge after intervention compared to pre intervention regarding definition, leading causes, predisposing factors, manifestation, diagnosis, treatment, complications, prevention, prognosis, dietary management, hygienic measures, dangerous signs, follow-up care, parents teaching and psychological support. These results supported by (15), who found that, the majority of studied nurses have satisfactory knowledge post intervention Regarding nurses' knowledge about role of multidisciplinary team in care of children with typhoid fever pre and post intervention of integrated clinical pathway, it was observed that, a highly statistical significance differences. This result in agreement with (20) in a study about "impact of designed nursing clinical pathway guidelines on the cardiac pacing patient outcomes" who stated that nurses with other multidisciplinary team management ensure the integrity for care of patients and their families through the use of integrated clinical pathway.

Regarding the relation between nurses' knowledge about integrated clinical pathway and implementation of integrated clinical pathway care map pre and post intervention. The result clarifies that, all studied nurses' knowledge were improved after intervention of integrated clinical pathway. This result agreed with (21) in a study about "quality of care for high risk neonates receiving total parenteral nutrition" who found that, there was a statistical significance difference between nurses' knowledge and their age. This result disagree with (17), who found that, there was no statistical significance difference between integrated clinical pathway and implementation of integrated clinical pathway care map pre and post intervention with personal characteristics of studied nurses.

Regarding the personal characteristics of studied children, the present study has also involved a group of children with typhoid fever for observation of nurses' performance. More than half of them were five to less than 15 years old, about two- thirds were females'. about two- thirds of these cases were date symptoms started are more than one week ago.These present study sample characteristics agree with (16) has mentioned that Symptoms usually develop 1-3 weeks after exposure, and may be mild or severe. They include high fever, malaise, headache, constipation or diarrhea.

\section{Conclusion}

Based on the results of the present study, it can be concluded that, the implementation of integrated clinical pathway is highly effective method to improve nurses' knowledge with concerning the integrated clinical pathway and its activities regarding care of children with typhoid fever.

\section{Recommendations}

Based on the findings of the current study the following recommendations are suggested: 
- The approach of care of integrated clinical pathway can be utilized by all health team members in the different health agencies as a routine care.

- Workshops and seminars should be organized with collaboration with different health team personals to raise their awareness about the desired outcomes of integrated clinical pathways for their profession, and to improve quality of care provided, decrease length of hospital stay, and therefore, increase children and their family satisfaction toward health care services.

- Provision of instructional booklet, colored posters, and preachers to nurses and children and their family members in typhoid fever units to increase health awareness and to improve their level of knowledge.

- Raise the awareness of multidisciplinary health team regarding integrated clinical pathway and its implementation for caring of children with typhoid fever.

- Further studies regarding implementation of integrated clinical pathway for different health status.

\section{Acknowledgements}

I express my gratitude and thank towards all nurses in Benha and Toukh fever hospitals who have directly helped us to complete this study and their support in each major step of the study. Also, I would like to thank hospitals administration who allowed us to conduct this study. We never forget to thank all studied children and their families for their kind help.

\section{Reference}

[1]. Karkey A, Thompson CN, Tran Vu Thieu N, Dongol S, Le Thi Phuong T, Voong Vinh P, et al.( 2013) Differential epidemiology of Salmonella Typhi and Paratyphi A in Kathmandu, Nepal: a matched case control investigation in a highly endemic enteric fever setting. PLoS Negl Trop Dis. 7(8):e2391.

[2]. Yanagi D, de Vries GC, Rahardjo D, Alimsardjono L, Wasito EB, De I, et. (2009): al. Emergence of fluoroquinolone-resistant strains of Salmonella enterica in Surabaya, Indonesia. Diagn Microbiol Infect

[3]. Parry CM, Threlfall EJ.( 2008): Antimicrobial resistance in typhoidal and nontyphoidal salmonellae. Curr Opin Infect Dis. Oct. 21(5):531-8

[4]. WHO position paper (2013): Typhoid vaccines', WKLy Epidemiology Rec. 83(6), pp: 49-59

[5]. WHO position paper (2 Effa EE, Lassi ZS, Critchley JA, et al.( 2011): Fluoroquinolones for treating typhoid and paratyphoid fever (enteric fever). Cochrane Database Syst Rev. Oct 5. CD004530.

[6]. Liao YS, Liang SY, Liao CH, et al.( 2013): Salmonella enterica serovar Typhi variants in long-term carriers. J Clin Microbiol. 2013 Feb. 51(2):669-72.

[7]. Hammond NE, Boyle M.( 2011): Pharmacological versus non- pharmacological antipyretic treatments in febrile critically ill patients: a systematic review and meta-analysis. Aust Crit Care. ;24:4-17. doi: 10.1016/j.aucc.2010.11.002.

[8]. Centre for Policy on Ageing, Glossary of health and social care, (2014): The effectiveness of care pathways in health and social care. Available at http://www.cpa.org.uk/glossary/glossary.html\#Care08

[9]. WHO (2010) Joint WHO/UNICEF Statement for vaccine use in tsunami affected areas Source: Available at http://www.who.int/cholera/tsunami_typhoidvaccine/en/print.html

[10]. Bowden V.R. \& Greenberg C.S. (2016): Pediatric Nursing Procedures, $4^{\text {th }}$ edition, China

[11]. National Leadership and Innovation Agency for Healthcare, (2005), Integrated Care Pathways; A guide to good practice, Innovation House, Bridgend Road, Llanharan, CF72 9RP, Wales

[12]. National health services, (2010): How to produce and evaluate an integrated care pathway (ICP): information for staff, August 2010

[13]. Panella, (2009): Variance analysis for integrated care pathways in Europe: methodologies, results, outcomes for patients and lessons learnt. Presentation to Change Champions, Melbourne. [Last accessed 24th August 2009] Available at http://www.changechampions.com.au/resource/Massimiliano_Panella.pdf

[14]. Abd-El Monen H, (2015): Effect of clinical pathway regarding to care of neonates on noninvasive continuous positive airway pressure. Unpublished Doctorate thesis, Faculty of Nursing, Ain Shams University, PP: 70-111.

[15]. Allah, S., (2013): Assessment of pediatric nurses' performance regarding oxygen administration therapy. Unpublished Master thesis, Faculty of Nursing, Ain Shams University, PP: 142-148.

[16]. Shahin, M., Mohammed, W., \& Sayed, M. (2012): Nurses' Knowledge and Practices regarding Enteral Nutrition at the Critical Care Department of Al-Manial University Hospital in Egypt: Impact of a Designed Instructional Program. Journal of American Science, 8 (11), 397-405.

[17]. Desoky S., (2012): Nursing care of children undergoing bone marrow transplantation, Unpublished Doctorate thesis, Faculty of Nursing, Ain Shams University, PP: 98-112.

[18]. El-haddy,S., (2009): Impact of a designed nursing clinical pathway on the outcomes of patients with acute heart failure at the critical care department of the El-Manial university hospital, Unpublished Doctorate thesis, Faculty of Nursing, Cairo University, P:98 Date accessed: 10 March 201

[19]. Nassar A., (2014): Effect of a clinical pathway on outcomes of children with hemolytic anemia, Unpublished Doctorate thesis, Faculty of Nursing, Ain Shams University, PP: 102-103.

[20]. Seloma Y., (2010): Impact of designed nursing clinical pathway guidelines on the cardiac pacing patient outcomes, Unpublished Doctorate thesis, Faculty of Nursing, Cairo University, PP: 102-103.

[21]. Abo- Zaid S., (2008): Quality of care for high risk neonates receiving total parenteral nutrition, Unpublished Master thesis, Faculty of Nursing, Ain Shams University, PP: 152-154. 